\title{
PENGEMBANGAN BUKU \\ PEDOMAN LAB ALAM \\ FAKULTAS ILMU SOSIAL \\ UNTUK SISWA SMP
}

\section{Artikel Penelitian}

\section{Nurul Ratnawati ${ }^{\star}{ }^{\star}$, Sukamto $^{1}$, I Nyoman Ruja ${ }^{1}$, Neni Wahyuningtyas ${ }^{1}$}

${ }^{1}$ Prodi Pendidikan IPS, FIS, Universitas Negeri Malang

Diterima 25 Juli 2017, Dipublikasikan 30 Oktober 2017

\begin{abstract}
Abstrak
Tujuan penelitian ini adalah menghasilkan buku pedoman laboratorium alam (fisik dan sosial) Fakultas IImu Sosial untuk siswa SMP sebagai suplemen dalam pembelajaran IPS Kelas VII semester 1 . Metode penelitian yang digunakan dalam penelitian ini adalah penelitian dan pengembangan (research \& development) dengan model 4-D (four D models). Model ini terdiri dari empat tahap yaitu: define (pendefinisian), design (perancangan), develop (pengembangan), dan disseminate (penyebaran) (Thiagarajan, 1974:5). Kelayakan buku divalidasi oleh ahli materi dan media pembelajaran. Skor validasi ahli materi sebesar $87,96 \%$ dan skor validasi ahli media pembelajaran sebesar $91,66 \%$. Berdasarkan hasil ini, dapat disimpulkan bahwa buku pedoman laboratorium alam yang dikembangkan telah valid dan layak.
\end{abstract}

\section{Kata kunci}

Pedoman, Lab Alam

\section{Abstract}

Purpose of this research is to produce guidelines for the use of natural labs Faculty of Social Sciences to be used by junior high school students as supplement in learning IPS Class VII semester 1. The research method used in this research is research \& development with $4-D$ (four $\mathrm{D}$ models). The model consists of four stages: define, design, develop, and disseminate. Book eligibility is validated by material experts and instructional media. Experimental material validation score of $87.96 \%$ and expert media learning validation score of $91.66 \%$. Based on these results, it can be saved

\section{Keywords}

Guidelines, Natural Labs

\section{A. Pendahuluan}

Visi dari Universitas Negeri Malang (UM) adalah menjadi perguruan tinggi unggul dan menjadi rujukan dalam penyelenggaraan Tridharma perguruan tinggi. Tridharma meliputi pendidikan, penelitian, dan pengabdian kepada masyarakat. Salah satu fakultas yang mengemban visi tersebut adalah Fakultas IImu sosial (FIS).

Perwujudan visi tersebut pada tingkat fakultas didukung dengan adanya sarana dan prasarana. Salah satunya adalah perpustakaan dan laboratorium. Laboratorium merupakan tempat ter- selenggaranya proses pembelajaran yang memadukan antara teori dan praktek. Laboratorium juga dapat diartikan sebagai suatu tempat di mana percobaan dan penyelidikan dilakukan. Laboratorium dalam pengertian sempit sering diartikan sebagai ruang atau tempat berupa gedung dibatasi oleh dinding dan atap yang di dalamnya terdapat sejumlah alat dan bahan praktikum. IImu-ilmu sosial mengkaji masyarakat dan kaitannya dengan lingkungan hidupnya. Oleh karena itu laboratorium ilmu-ilmu sosial tidak hanya berupa gedung atau ruang yang dibatasi dinding dan atap, tetapi juga

\footnotetext{
${ }^{1}$ Surel korespondensi: nurul.ratnawati.fis@um.ac.id
} 
laboratorium berupa ruang terbuka atau alam terbuka (di lapangan) baik secara fisik maupun masyarakat.

Laboratorium sangat diperlukan sebagai tempat belajar untuk memberikan pengalaman nyata pada peserta didik sebagai salah satu faktor pendukung pelaksanaan pembelajaran. Kegiatan laboratorium tidak hanya bertujuan untuk meningkatkan teori, tetapi siswa dapat menemukan pengetahuan sendiri (Feyzioglu, 2009). Menurut Tobin dalam Hofstein dan Lunetta (2003) kegiatan laboratorium digunakan sebagai cara agar peserta didik mudah memahami materi serta dapat membangun pengetahuan dengan mengalami proses atau percobaan sendiri. Pernyataan tersebut dapat diartikan bahwa melalui kegiatan di laboratorium siswa dapat membangun sendiri pengetahuan tentang fakta, konsep, dan teori yang terdapat dalam materi serta memperkaya pengalaman mereka, sehingga pengalaman-pengalaman nyata tersebut akan bertahan lebih lama dalam ingatan siswa.

Laboratorium alam atau lapangan adalah kebutuhan mendesak bagi ahli-ahli ilmu-ilmu sosial. Adanya laboratorium alam yang sekaligus sebagai tempat wisata berbasis multikultur diperlukan untuk mengaplikasikan teori, meningkatkan kemampuan proses, kemampuan menyelesaikan masalah, dan meningkatkan minat serta sikap mahasiswa terhadap pembelajaran. Keberadaan laboratorium alam dapat dijadikan sebagai media pembelajaran dan mendukung kegiatan pembelajaran serta mencapai tiga ranah tujuan pendidikan yaitu kognitif, afektif dan psikomotorik (Hofstein dan Naaman, 2007).

Kurikulum 2013 menuntut pembelajaran kontekstual, kontruktivistik, dimana peserta didik dituntut untuk mencari tahu (bukan diberitahu) serta menemukan sendiri melalui pendekatan ilmiah (scientific approach). Dalam pembelajaran tersebut dukungan laboratorium alam sangat diperlukan. Laboratorium alam sebaiknya dipilih pada suatu daerah yang kompleks yang dapat dimanfaatkan secara bersama, sehingga lebih terfokus dan efisien.

Lereng Selatan Gunung Kelud Kabupaten Blitar merupakan kawasan yang mempunyai banyak potensi untuk dikembangkan sebagai laboratorium alam ilmu sosial karena beberapa potensi yang dimiliki. Kajian awal pada wilayah lereng selatan Gunung Kelud meliputi kecamatan Nglegok, Gandusari, dan Garum sebagai tempat kajian atau laboratorium alam sudah dilakukan pada tahun 2014. Obyek-obyek yang menjadi fokus kajian tersebar dalam ruang di ketiga wilayah kecamatan tersebut. Masing-masing obyek memiliki karakteristik tertentu yang relevan dengan kajian matakuliah tertentu pula. Namun ada pula obyek yang relevan atau dapat dikaji oleh beberapa matakuliah dalam jurusan tertentu atau bahkan dapat dikaji dari beberapa jurusan yang ada lingkungan FIS.

Berdasarkan hasil penelitian tahap pertama yang sudah dilakukan oleh para peneliti FIS, diperoleh beberapa objek yang berpotensi sebagai laboratorium alam Fakultas IImu Sosial Universitas Negeri Malang. Potensi objek laboratorium alam dibagi menjadi tiga kategori, berupa kategori laboratorium alam fisik, laboratorium alam sosial, dan laboratorium alam sejarah. Dari hasil tersebut tentunya sangat mendesak sekali untuk dikembangkan buku panduan laboratorium lapangan khususnya untuk mata pelajaran IPS. Berbeda dengan penelitian sebelumnya yang telah berhasil mengembangkan Buku Pedoman Laboratorium IPS Terpadu Kontekstual di Lereng Selatan Gunung Kelud Blitar yang akan digunakan oleh mahasiswa. Maksud dari penelitian ini adalah memberikan informasi-informasi tentang fenomen-fenom en a fisik (nature dan culture) di Lereng Selatan Gunung Kelud yang diramu dalam sebuah buku pedoman, khususnya buku pedoman bagi siswa SMP.

\section{B. Metode Penelitian}

Desain penelitian yang digunakan dalam penelitian ini adalah penelitian pengembangan sesuai dengan desain Thiagarajan yang menghasilkan produk berupa prototype buku pedoman laboratorium alam (fisik dan sosial) FIS untuk siswa SMP. Rancangan penelitian ini menggunakan rancangan penelitian pengembangan model 4-D (four $D$ models). Model ini terdiri dari empat tahap yaitu: define (pendefinisian), design (perancangan), develop (pengembangan), dan disseminate (penyebaran) (Thiagarajan, 1974:5). Secara detail mengenai tahapan pengembangan buku siswa dan buku guru yang dikembangkan peneliti sesuai dengan model 4-D ini dapat dilihat pada diagram yang ditunjukkan pada Gambar 1. Mengingat keterbatasan waktu, penelitian ini hanya sampai pada tahap III develop yaitu sampai validasi ahli materi dan media pembelajaran.

Metode yang digunakan untuk validasi buku pedoman laboratorium alam menggunakan angket. Analisis instrumen angket digunakan untuk menguji kelayakan produk berupa buku pedoman laboratorium alam. Instrumen angket ini menggunakan 
skala likert. Katergori jawaban yang disediakan yaitu tidak baik dengan bobot 1 , cukup baik dengan bobot 2, baik dengan bobot 3 , dan sangat baik dengan bobot 4. Hasil skor dari validasi yang dilakukan oleh validator.

$$
P=f / n \times 100 \%
$$

Keterangan:

(Sudijono, 2008)

$\mathrm{f}=$ frekuensi

$\mathrm{n}=$ jumlah frekuensi maksimal

$\mathrm{P}=$ persentase

Tabe I1. Kriteria Kelayakan Produk

\begin{tabular}{ll}
\hline \multicolumn{1}{c}{ Skor Angket } & \multicolumn{1}{c}{ Kriteria } \\
\hline $81,25 \%<$ skor $\leq 100 \%$ & sangat baik \\
$62,50 \%<$ skor $\leq 81,25 \%$ & baik \\
$43,75 \%<$ skor $\leq 62,50 \%$ & cukup baik \\
$25 \%<$ skor $\leq 43,75 \%$ & kurang baik \\
\hline
\end{tabular}

\section{Hasil dan Pembahasan}

\section{Tahap Pendefinisian}

Tahap pendefinisian tediri dari lima langkah, yaitu analisis awal akhir, analisis siswa, analisis tugas, analisis konsep, dan analisis tujuan pembelajaran. Analisis awal akhi bertujuan untuk menetapkan masalah dasar yang dihadapi dalam pembelajaran, khususnya pembelajaran IPS. Berdasakan hasil analisis, selama ini buku yang dijadikan pedoman guru dalam pembelajaran IPS hanya buku yang diterbitkan oleh pemerintah yaitu buku siswa dan buku guru. Oleh sebab itu dirasa perlu untuk mengembangkan buku suplemen beupa buku pedoman laboratorium alam (fisik dan sosial) Fakultas IImu Sosial untuk siswa SMP guna menunjang tercapainya tujuan pembelajaran siswa di sekolah-sekolah sekitar laboratoium alam FIS, apalagi setiap sekolah telah menerapkan kurikulum 2013.

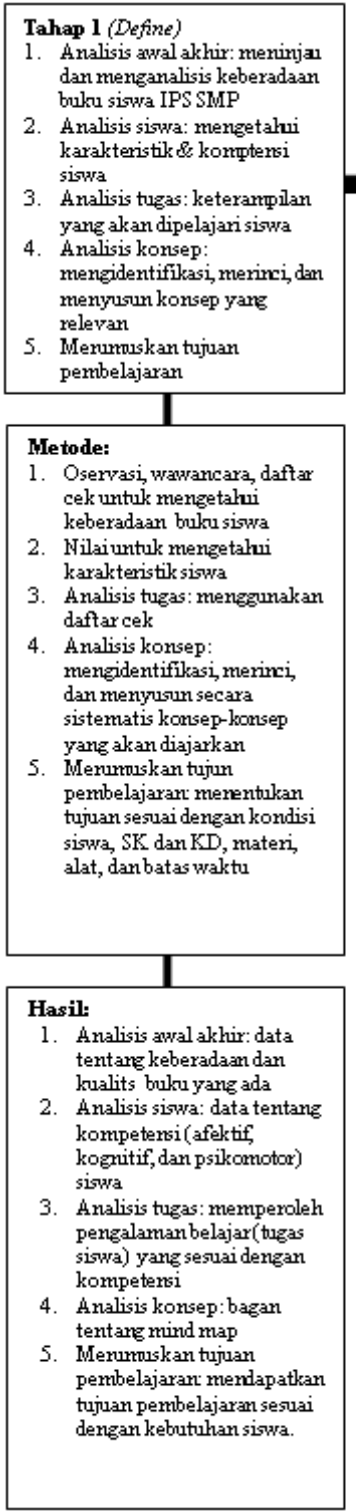

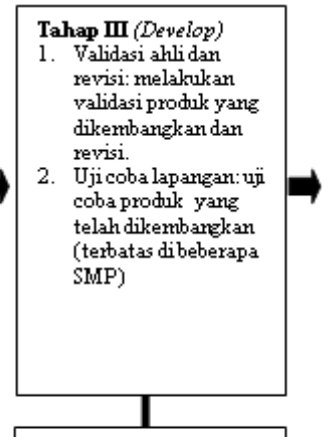

Metode:

1. Penyusuman tes: membuat kisi-kisi tes

2. Pemilihanmedia: sesuai dengan analisis tugas dan analisis materi, dan fasilitas di sekolah

3. Pemilihanfomat: pemilihan format sesuai dengan pendekatam strategi, model, dan metode yang dipilih

4. Perancargan awal dibuat dengan cara mempertimbangkan Denglaptaimf pengadaptaian format mebaca buka-buka disusi dengan tir peneliti

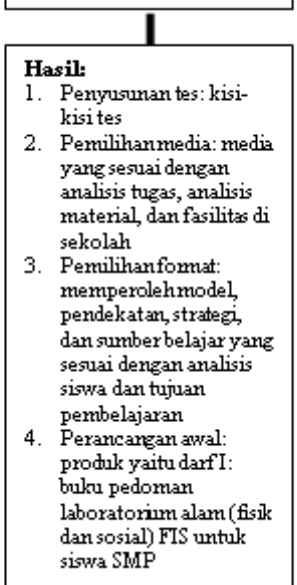

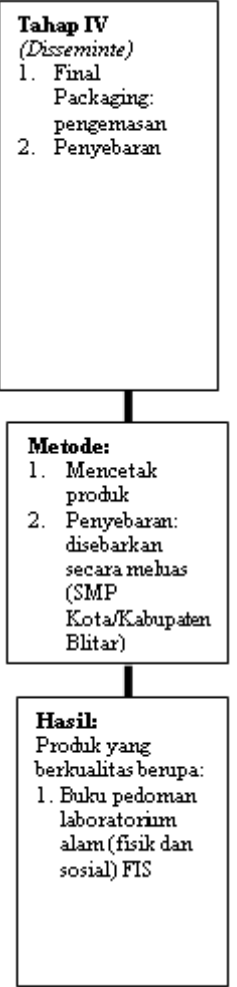

Gam bar 1. Desain Pengembangan 4-D 
12 | Nurul Ratnawati, dkk, Pengembangan Buku Pedoman Lab Alam Fakultas IImu Sosial ...

Analisis siswa dilakukan dengan tujuan untuk mengetahui karakteristik, kondisi, pengetahuan, perkembangan, kemampuan serta pengalaman siswa dalam memahami bahan ajar. Analisis siswa ditujukan untuk siswa kelas VII sebagai subjek penelitian yang memiliki usia antara 12-13 tahun. Menurut Piaget (dalam Nursalim, 2007) anak pada usia 12 tahun sampai dewasa merupakan tahap operasional formal, dimana anak telah memiliki kemampuan untuk melakukan penalaran, dapat berfikir secara abstrak, menalar secara logis, dan menarik kesimpulan informasi yang tersedia. Berdasarkan pernyataan tersebut maka dapat diajadikan dasar dalam merumuskan bahan ajar yang dapat menarik perhatian siswa dalam mencari kaitan-kaitan, menemukan fakta, konsep, prosedur, memecahkan suatu masalah, dan menyelesaikan tugas-tugas.

Analisis tugas adalah alat yang digunakan oleh guru dalam menentukan isi pembelajaran yang akan diajarkan kepada siswa. Analisis tugas dilakukan untuk menyusun isi materi atau tugas-tugas yang harus dilakukan siswa secara garis besar dan pembuatan soal-soal untuk evaluasi pembelajaran. Dalam analisis tugas akan menampilkan kegiatan belajar atau aktivitas belajar siswa.

Analisis konsep bertujuan untuk mengidentifikasi konsep materi yang relevan. Analisis konsep diawali dengan menyusun materi secara sistematik dalam bentuk peta konsep yang didasarkan pada KI dan KD. Peta konsep disusun bertujan untuk mengidentifikasi konsep-konsep materi yang akan disampaikan pada proses pembelajaran. Dan tahap yang teakhir pada tahap pendefinisian adalah analisis tujuan pembelajaran. Analisis tujuan pembelajaan digunakan sebagai dasar dalam penyusunan materi dan soal latihan.

\section{Tahap Perancangan}

Tahap perancangan ini bertujuan untuk merancang buku pedoman laboratorium alam (fisik dan sosial) Fakultas IImu Sosial. Secara garis besar, tahap perancangan ini meliputi dua langkah yaitu pemilihan format dan desain. Format buku pedoman laboratorium alam yang dirancang ini mengikuti fomat penyusunan bahan ajar pada umumnya. Mendesain buku merupakan kegiatan merancang model buku atau fisik buku agar lebih menarik dan memotivasi siswa untuk belajar.

Tahap ini diawali dengan pembuatan kerangka buku. Format buku terdiri dari bagian pembuka dan bagian inti. Bagian pembuka terdiri dari sampul depan, halaman sampul, kata pengantar, daftar isi, tentang buku pedoman laboratorium alam, ke- terkiatan KD dengan tema, serta peta konsep. Kegiatan inti terdiri dari 2 kegiatan pembalajaran yaitu pembelajaran 1 dan pembelajaran 2. Di awal kegiatan pembelajaran terdapat tujuan pembelajaran yang harus dicapai siswa. Pada pembelajaran 1 menyajikan 7 kegiatan pembelajaran yang diterjemahkan melalui sub judul 1) ayo mengamati, 2) ayo membaca, 3) ayo menanya, 4) ayo diskusi, 5) ayo menalar, 6) ayo renungkan, dan 7) uji kompetensi. Sementara pada pembelajaran 2 menyajikan 5 kegiatan pembelajaran seperti pembelajaran 1 tanpa kegiatan ayo mengamati dan ayo membaca.

\section{Tahap Pengembangan}

Tahap pengembangan bertujuan untuk menghasilkan buku pedoman laboratorium alam (fisik dan sosial) Fakultas IImu Sosial untuk siswa SMP yang layak. Kelayakan buku pedoman ini diukur melalui validasi ahli yaitu ahli materi dan ahli media. Hasil uji validasi materi diperoleh persentase sebesar $72,22 \%$ pada validasi tahap awal, dan sebesar $87,96 \%$ pada validasi ke-dua. Sedangkan hasil uji validasi media pembelajaran diperoleh persentase sebesar $61,11 \%$ pada validasi tahap awal, dan sebesar $91,66 \%$ pada validasi ke-dua. Komentar dan saran dari validator ahli materi dan media pembelajaran dapat dilihat pada tabel 2 .

Tabe I2. Komentar Validator Ahli Materi dan Media

\begin{tabular}{ll}
\hline Validator & Komentar dan Saran \\
\hline Ahli Materi & Materi sebaiknya lebih dipadukan \\
& dengan pendekatan IPS (multidipliner); \\
& peta konsep kurang begitu jelas; \\
& petunjuk penggunaan buku (tentang \\
& buku) sebaiknya dibuat lebih jelas. \\
\hline Ahli Media & Tampilan cover harap dikontraskan agar \\
Pembelajaran & lebih proporsional; mengingat \\
& sasarannya adalah siswa SMP, maka \\
& pemilihan jenis huruf dan kombinasi jenis \\
& huruf harap disesuaikan dengan karakter \\
& siswa; tambahkan gambar agar \\
& membangkitkan motivasi siswa. \\
\hline
\end{tabular}

Berdasarkan hasil ini, dapat disimpulkan bahwa buku pedoman laboratorium alam yang dikembangkan telah valid dan layak untuk diujicobakan ke tahap selanjutnya (uji coba lapangan skala kecil). Seperti yang telah dikemukakan di awal kerena keterbatasan waktu penlitian, maka uji coba lapangan skala kecil dan skala luas akan dilakukan pada penelitian selanjutnya.

Hasil pengembangan berupa buku pedoman laboratorium alam (fisik dan sosial) Fakultas IImu Sosial untuk siswa SMP ini dikemas dalam bentuk serangkaian aktivitas penelitian kecil yang harus dilakukan siswa dan masalah yang memuat 
tuntutan untuk berfikir sehingga mengarah pada student centered (pembelajaan yang bepusat pada siswa). Hal tersebut sejalan dengan paradigma kuikulum 2013 yang menekanan penggunaan pendekatan saintifik yang terdiri dari lima aktivitas belajar (5M), yakni mengamati, bertanya, melakukan percobaan atau mencari informasi, melakukan penalaran atau asosiasi untuk mengolah informasi dan mengembangkan jaringan atau mengomunikasikan hasil investigasi (Sani, 2014).

Guru bukanlah satu-satunya sumber belajar. Oeh sebab itu dengan dihasilkannya buku pedoman laboratoium ini sebagai sumber belajar atau lebih dikenal dengan istilah media pembelajaran, diharapkan dapat membantu memudahkan guru dalam mencapai tujuan belajar siswa. Buku pedoman laboratorium alam yang telah dikembangkan ini termasuk dalam kategori media pembelajaran visual. Munadi (2008) menyatakan bahwa media visual merupakan media pembelajaran yang hanya melibatkan indera penglihatan dan yang termasuk dalam media pembelajaran visual antara lain buku, modul, komik, poster, peta, dan bagan.

Buku pedoman laboratorium alam sebagai media pembelajaan ini memiliki beberapa kelebihan dan kelemahan. Kelebihan buku pedoman laboratorium alam ini antara lain 1) menyajikan materi yang benar-benar dekat dengan siswa (kontekstual), 2) menggunakan pendekatan saintifik sesuai dengan kuikulum 2013,3) menyajikan contoh-contoh permasalahan yang bevaiasi, 4) menggunakan tata bahasa yang komunikatif dan mudah dipahami, dan 5) uraian kegiatan mengajak siswa untuk aktif dalam pembelajaran. Beberapa hal tesebut sejalan dengan pendapat Bruner dalam teorinya Free Discovery Learning, bahwa proses belajar akan berjalan dengan baik dan kreatif jika guru memberikan kesempatan kepada siswa untuk aktif menemukan suatu konsep, teori, aturan, atau pemahaman melalui contoh-contoh yang ia jumpai dalam kehidupan sehari-hari (Silalahi, 2011).

Sedangkan kelemahan buku pedoman laboratoium alam ini antara lain 1) buku ini tidak bisa digunakan secara umum atau luas di seluruh sekolah, karena buku pedoman ini khusus dikembangkan untuk sekolah-sekolah di sekitar laboratoium alam FIS tepatnya di lereng selatan Gunung Kelud; 2) buku ini masih tegolong dalam kate- gori media visual, sehingga perlu dikembangkan lebih lanjut sesuai dengan kemajuan teknologi saat ini sehingga bisa dibaca kapan saja, dimana saja, dan oleh siapa saja.

\section{Penutup}

Kelayakan buku divalidasi oleh ahli materi dan media pembelajaran. Skor validasi ahli materi sebesar $87,96 \%$ dan skor validasi ahli media pembelajaran sebesar $91,66 \%$. Berdasarkan hasil ini, dapat disimpulkan bahwa buku pedoman laboratorium alam yang dikembangkan telah valid dan layak.

\section{E. Daftar Pustaka}

Feyzioglu B. 2009. An Investigation of The Relationship Beetwen Science Process Skills with Efficient Laboratory Use and Science Achievement in Chemistry Education. Journal of Turkish Science Education, (Online) 6 (3):114-132, (http://www.tused.org/internet/tused/archive/v6 /i3/ text/tusedv6i3s10.pdf), diakses 24 Januari 2017.

Hofstein A. \& Lunetta V.N. 2003. The Laboratory In Science Education: Foundation For The $21 \mathrm{st}$ Century. Science Education, (Online) 88:2854 , (http://gpquae.iqm.unicamp.br/gtexperimentac ao.pdf), diakses 24 Januari 2017.

Hofstein A. \& Naaman R.M. 2007. The Laboratory In Science Education: The State of The Art. Journal of Chemitry Education and Prctice, (Online) 8 (2):105-107, (http://www.rsc.org/images/Hofstein\%20intro \%20final_tcm18-85027.pdf), diakses 24 Januari 2017

Sani, Ridwan, Abdullah. 2014. Pembelajaran Saintifik untuk Implementasi Kurikulum 2013. Jakarta: Bumi Aksara.

Silalahi, R. 2011. Kontribusi Model Pembelajaran Kontekstual Tipe Inkuiri dalam Meningkatkan Motivasi dan Prestasi Belajar Siswa pada Mata Pelajaran Pendidikan Kewaganegaraan. Edisi Khusus, No. 2 (Jurnal UPI)

Thiagarajan, S, Semmel dan Semmel, 1974. Instructional Development for Training Teacher of Exceptional Children. Minnesota: Indiana University. 